MONOGRÁFICO

LA ADMINISTRACIÓN FISCAL EN IBEROAMÉRICA:

INSTITUCIONES, OFICINAS

Y FUNCIONARIOS, SIGLOS XVIII-XX 


\title{
"EL GOBIERNO SIN ADMINISTRACIÓN, ES COMO UN ASTRÓNOMO SIN TELESCOPIO, O PILOTO SIN TIMÓN" \\ LA ADMINISTRACIÓN FISCAL EN IBEROMAÉRICA: INSTITUCIONES, OFICINAS Y FUNCIONARIOS, SIGLOS XVIII-XX
}

\author{
LUIS JÁUREGUI \\ Instituto de Investigaciones Dr. José María Luis Mora, México \\ ljauregui@mora.edu.mx \\ Carlos de Jesús Becerril Hernández \\ Facultad de Derecho, Universidad Anáhuac México, México \\ carlos.becerrilh@anahuac.mx
}

https://doi.org/10.36105/iut.2021n33.01

Un plan de Hacienda debe entrañar un arreglo administrativo de las municipalidades, de los procedimientos judiciales, de la estadística, del comercio, de la minería, de los oficios de hipotecas, de la policía en varias de sus ramificaciones, de la diplomacia en cuanto tiene por objeto las relaciones comerciales, del crédito público y otros muchos ramos, y todo con tal enlace que el menor descuido en los pormenores podría comprometer todo el éxito del conjunto.

Olasagarre, Manuel de Jesús, Informe que por orden de Su Alteza Serenísima presenta al supremo gobierno sobre el estado de la Hacienda pública y sus reformas, México, Imprenta de Ignacio Cumplido, 1855, p. 12.

La historia de la Hacienda Pública ha sido uno de los temas más socorridos dentro de la historiografía económica iberoamericana. Desde las últimas décadas del siglo $\mathrm{Xx}$, han visto la luz estudios que se dedican a explicar el desempeño fiscal 
de las posesiones españolas y portuguesas, así como de las naciones independientes que surgieron de ellas en diversos periodos históricos. El análisis ha sido desde la perspectiva de los ingresos, los egresos y, en menor medida, la deuda pública. En pocos casos, se ha estudiado la administración fiscal como el instrumento por el cual los países de la región han acopiado y distribuido sus recursos. Resulta por lo mismo indispensable el análisis de las instituciones, las oficinas y los funcionarios que se han encargado de definir las facultades de gobierno encaminadas al buen funcionamiento de los erarios nacionales. En general, en este Monográfico se busca entender el largo proceso de administrativización de la Hacienda Pública; es decir, cómo se fueron sometiendo sus operaciones a procesos legales y reglamentarios, en la búsqueda de procedimientos administrativos eficientes y capaces de incrementar la recaudación y distribuirla para los fines de la sociedad (o de los grupos dominantes de la sociedad). Se trata de un trabajo colectivo que brinda un enfoque desde la perspectiva de la administración fiscal, de tal forma que permita comprender cómo se entremezclaban la legislación, el desempeño económico y la fiscalidad.

Definido como "aquella rama del derecho administrativo que expone las normas y los principios relativos a la imposición y la recaudación de los tributos y que analiza las consiguientes relaciones jurídicas entre los entes públicos y los ciudadanos", 1 el derecho fiscal o tributario es una de las herramientas más importantes con las que cuenta la administración pública para obtener los recursos pecuniarios que le permitan llevar a cabo sus funciones. De hecho, la obligación de contribuir a los gastos públicos se encuentra presente en todos los ordenamientos jurídicos tanto virreinales como nacionales iberoamericanos.

¿Tributar o no tributar? Esa no es cuestión, pues la historia fiscal nos demuestra que, quizá, el pago de impuestos sea algo que comparten todas las civilizaciones del mundo sin importar tiempo y espacio. ${ }^{2}$ El diseño de una política fiscal que permita recaudar más afectando lo menos posible a los contribuyentes ha sido un fin deseado por todos los órganos políticos encargados de cobrar impuestos. El caso iberoamericano destaca por una profunda dependencia de las contribuciones indirectas y el tortuoso camino para instaurar las directas. ${ }^{3}$ En medio del constante acoso de la guerra, los fiscos americanos no pudieron vencer la dependencia de la trayectoria proveniente del período virreinal hasta bien entrado el siglo XIX. ${ }^{4}$ No importaba que reformas se llevasen a cabo, la mayoría de

1 Giannini, Achille Donato, Instituciones de Derecho Tributario, Madrid, Editorial de Derecho Financiero, 1957, p. 7.

2 Para el caso internacional véase Comín Comín, Francisco, Historia económica mundial. De los orígenes a la actualidad, España, Alianza Editorial, 2011. Un estudio sobre el desempeño económico nacional se encuentra en CÁrdenas SÁnchez, Enrique, El largo curso de la economía mexicana. De 1780 a nuestros días, México, El Colegio de México, Fondo de Cultura Económica, 2015.

3 Jáuregui, Luis (coord.), De riqueza e inequidad. El problema de las contribuciones directas en América Latina, siglo XIX, México, Instituto Mora, 2006.

4 Cfr. Aboites Aguilar, Luis y Jáuregui, Luis (coords.), Penuria sin fin. Historia de los impuestos en México siglos XVIII-XX, México, Instituto Mora, 2005; Llopis, Enrique y MARICHAL, Carlos (coords.), Latinoamérica y España 1800-1850. Un crecimiento económico nada excepcional, México-España, Instituto Mora, Marcial Pons, 2009. 
ellas fracasaron en su intento de dotar de un sistema fiscal eficiente a sus respectivos gobiernos. ¿Por qué?

La respuesta puede encontrarse en la incapacidad de los estados iberoamericanos de establecer un gobierno fuerte que fuese capaz de imponerse a los grandes agentes económicos que no estaban dispuestos a ser fiscalizados con más contribuciones que las que habían pagado durante la administración española y portuguesa. De ahí que, como hemos dejado claro en otros trabajos, nos encontramos frente a problemas comunes y, por lo tanto, soluciones compartidas. ${ }^{5}$ ¿Cuál era el remedio contra los fracasos legislativos iberoamericanos en materia fiscal? La solución vendría de la Francia revolucionaria donde surgió una herramienta que cambiaría para siempre el rostro del derecho proveniente del antiguo régimen: el derecho administrativo. ${ }^{6}$

Concebido por el jurista mexicano Teodosio Lares (1806-1870) como "la ciencia de la acción y de la competencia del poder ejecutivo, de sus agentes, y de los tribunales administrativos, en relación con los derechos e intereses de los ciudadanos, y con el interés general del Estado", ${ }^{7}$ el derecho administrativo y su jurisdicción contenciosa marcaron el inicio de una nueva etapa en la historia del derecho mundial. $^{8}$

Desde entonces, la racionalidad administrativa y la administrativización de la Hacienda Pública se convirtieron en la solución para la problemática fiscal. ${ }^{9}$ "Orden administrativo y directivo de las rentas públicas: en estas pocas palabras me aventuro a asegurar se encierra el porvenir de México, es preciso establecer radicalmente el orden en la administración", ${ }^{10}$ fue la consigna de Manuel Olasagarre, ministro de Hacienda de Antonio López de Santa Anna, pues antes de reformar cualquier figura impositiva había que administrar bien tanto la recaudación de los impuestos como el ejercicio del gasto público, manteniendo el equilibro entre estos y la contratación de deuda.

El presente Monográfico surge de una sesión del Sexto Congreso Latinoamericano de Historia Económica (CLADHE VI) llevado a cabo en Santiago de

5 Jáuregui, Luis y BeCERril Hernández, Carlos de Jesús, "Diseños y transiciones fiscales en Iberoamérica, siglos XVII-XX (problemas comunes, soluciones compartidas), en JÁUREGUI, Luis y BECERRIL HERNÁNDEZ, Carlos de Jesús (coords.), Fiscalidad iberoamericana, siglos XVII-XX. Transiciones, diseños administrativos y jurídicos México, Instituto Mora, Universidad Anáhuac México, 2018, pp. 7-28.

6 Cfr. MAnnori, Luca, "Justicia y Administración entre Antiguo y Nuevo Régimen”, Revista Jurídica, Universidad Autónoma de Madrid, núm. 15, 2007, Madrid, pp. 126-146.

7 Lares, Teodosio, Lecciones de Derecho Administrativo, México, Imprenta de Ignacio Cumplido, 1852, p. 2.

8 Marta Lorente afirma que "en su día, la creación de una jurisdicción `administrativa' levantó una doble frontera, cronológica y geográfica, que alejará a las formaciones estatales que la acogieron tanto de su más reciente pasado cuanto de otras que, como las anglosajonas, rechazaron la implantación de aquella "solución jurisdiccional". Lorente, Marta, "Presentación", en LoRente, Marta (coord.), La jurisdicción contencioso-administrativa en España. Una historia de sus orígenes, España, Consejo General del Poder Judicial, 2009, p. 15.

9 Becerril Hernández, Carlos de Jesús, “Administrativizar la Hacienda pública. La legislación tributaria del régimen santannista, 1853-1855”, Legajos. Boletín del Archivo General de la Nación, Séptima Época, año 4, núm. 16, abril-junio, 2013, México, pp. 35-60.

10 Olasagarre, Manuel de Jesús, Informe que por orden de Su Alteza Serenísima presenta al supremo gobierno sobre el estado de la Hacienda pública y sus reformas, México, Imprenta de Ignacio Cumplido, pp. 2 y 9. 
Chile, los días 23-25 de julio de 2019. La crisis sanitaria mundial provocada por el COVID-19 alargó la publicación de esta obra. No obstante, los autores agradecemos a la Revista Iuris Tantum de la Facultad de Derecho de la Universidad Anáhuac México por permitirnos publicar nuestras reflexiones en torno a la administración tributaria que, indudablemente conjugan historia, derecho y fiscalidad, para dar respuesta a una nueva línea de investigación denominada historia del derecho fiscal, cultivada, consciente e inconscientemente, por todos los autores que escriben en este número y por nosotros, que tenemos el honor de coordinarlo.

¿Cómo se construyeron y evolucionaron las instituciones hacendísticas nacionales? ¿Acaso la atonía fiscal que viven nuestros países tiene sus raíces en un diseño administrativo inapropiado o inflexible? Tal atonía ¿Tiene explicaciones técnicas o se deben considerar los aspectos políticos, sociales y culturales?; fueron las preguntas que nos guiaron en aquel encuentro desde el finis terrae. De dichas reflexiones se desprenden tres variables que son comunes a los trabajos aquí presentados: las instituciones, los funcionarios y las oficinas.

En cuanto hace al primer aspecto, las instituciones, es importante señalar que muchas de ellas sobrevivieron a las independencias iberoamericanas. Con la excepción de Brasil, en donde se mantuvo la monarquía hasta finales del siglo XIX, todas ellas pasaron de ser parte de la Real Hacienda a formar su propia Hacienda Pública Nacional. No obstante, como lo señalan Bruno Aidar, Cláudia Chaves y Marcia Eckert, pese a que la crisis trasatlántica ocasionada por la invasión del ejército napoleónico a la península ibérica, no tuvo como consecuencia la independencia de Brasil, como sí sucedió en el caso de la América española, el traslado de la familia real portuguesa a su colonia americana en 1808, la revolución liberal de Oporto en 1820, así como el propio proceso de independencia brasileña tuvieron como consecuencia la reforma del Erario Regio al de Tesoro Nacional. Dichas transformaciones institucionales buscaban la instauración de un régimen fiscal liberal que gravara el producto de la riqueza y no la riqueza en sí. Un problema compartido con el caso mexicano, pues como lo demuestra Luis Jáuregui en su texto, diversos problemas administrativos de la última Nueva España fueron heredados al nuevo país, entre ellos destacan el asunto de los problemas derivados de la Guerra de Independencia (1810-1821) que marcarían el trágico destino de la Hacienda Pública Mexicana. La aparición de una contabilidad más elaborada, así como la de intermediarios fiscales otrora no contemplados como los municipios y las diputaciones provinciales, vinieron a fragmentar al fisco virreinal y a comenzar a definir un espacio administrativo bien delimitado de la competencia fiscal de las autoridades exactoras y de la jurisdicción administrativa encargada de dirimir las controversias derivadas del pago de los impuestos, antes retenida en la Real Hacienda Novohispana. "Centralización política, descentralización fiscal", fue la consigna que el gobierno colombiano introdujo por medio de la Constitución de 1886. ¿Cómo lograr esta consigna en medio de una constante guerra civil y un desempeño económico poco favorable? Edwin López Rivera nos muestra el caso del Departamento de Cundinamarca en Colombia, 
dejándonos ver cómo un gobierno local pudo resistir el cambio en la forma de administrar y ejecutar el gasto al menos hasta 1910.

En segundo lugar, los funcionarios y las oficinas, también se muestran como un agente protagónico en el pago de los impuestos. Ernest Sánchez analiza el papel del comisario de guerra en Nueva España, un trabajo clave para entender el diseño institucional de una figura que era coadyuvante en el control del gasto militar, principal fuente de egresos tanto de la Real Hacienda como más tarde la Hacienda Pública Nacional. En este sentido, cobra relevancia el inicio de la jurisdicción contencioso administrativo fiscal, pues es obvio que, por primera vez se separó lo administrativo fiscal de la justicia en general, como antaño no sucedía. ${ }^{11}$ Separación que confirmó a la autoridad fiscal como aquella con competencia para cobrar los impuestos y a la judicial con la jurisdicción para dirimir las controversias derivadas de dichos actos. ${ }^{12}$ Es precisamente esta característica la que justifica el sistema de acreditamiento del Impuesto al Valor Agregado a finales del siglo xx, pues por la vía administrativo-fiscal, afirma María del Ángel Molina Armenta, se pueden entender las cuestiones económicas y políticas de la administración fiscal mexicana. Problemáticas que, de hecho, convirtieron al IVA, junto con el Impuesto Sobre la Renta, en los pilares de la fiscalidad mexicana.

¿Qué enseñanzas nos dejan los trabajos que componen este Monográfico? En primer lugar, la historia fiscal nos permite observar que para hacer eficiente el pago de impuestos no es necesario reformar las figuras impositivas, pues esto no hace per se que la recaudación aumente, lo verdaderamente importante es lograr que las instituciones, las oficinas y los funcionarios establezcan una dinámica de administrativización de la Hacienda Pública que permitan la celeridad y regularidad de los procesos administrativo-fiscales. De esta forma, el contribuyente tendrá herramientas que le permitan pagar de manera eficiente sus impuestos, tener medios de defensa y, quizá lo más importante, verificar la correcta administración del gasto público. No es casualidad que, hasta ahora, la reforma fiscal en México pueda describirse como una "crónica de los deseos no cumplidos", pues se ha optado por una reforma administrativa que, dicho sea de paso, ha sido exitosa para el estado mexicano. ${ }^{13}$ ¿También lo es para el contribuyente? Es una pregunta que un estudio sobre fiscalidad contemporánea podría contestar.

No nos resta más que agradecer a la Facultad de Derecho de la Universidad Anáhuac México por brindarnos este espacio para reflexionar sobre una temática común a Iberoamérica, la fiscalidad como parte de la construcción del estado

11 Un trabajo reciente sobre el tema se encuentra en BeCERril HernáNDEZ, Carlos de Jesús, "La jurisdicción contencioso administrativa fiscal en México, 1879", en Historia y Memoria. El régimen de Porfirio Díaz, México, El Colegio de San Luis, Instituto de Investigaciones Dr. José María Luis Mora, Instituto de Investigaciones Históricas de la Universidad Michoacana de San Nicolás de Hidalgo, 2021, en prensa.

12 Un acercamiento a esta problemática se encuentra en BeCERril Hernández, Carlos de Jesús, "Competencia y jurisdicción de la Real Hacienda en Indias. La parte procesal de la fiscalidad: Nuevo Reino de Granada, 1793", en SÁnchez SAntiró, Ernest (coord.), Gobierno y la administración de los erarios regios de la Monarquía Católica, México, Instituto de Investigaciones Dr. José María Luis Mora, 2021, en prensa.

13 "Crecen ingresos tributarios sobre Hacienda", El Financiero, 31 de agosto de 2021. https://www.elfinanciero. com.mx/economia/2021/08/31/crecen-ingresos-tributarios-sobre-hacienda/ 
nacional. Lanzamos nuevamente una invitación a los colegas iberoamericanos para escribir una historia general de la fiscalidad de nuestra región, creemos que la disciplina ha madurado lo suficiente como para acometer esta tarea.

\section{BIBLIOGRAFÍA}

\section{Hemerografía}

El Financiero

\section{Fuentes consultadas}

Aboites Aguilar, Luis y Jáuregui, Luis (coords.), Penuria sin fin. Historia de los impuestos en México siglos XVIII-XX, México, Instituto Mora, 2006.

BeCERril Hernández, Carlos de Jesús, "Administrativizar la Hacienda pública. La legislación tributaria del régimen santannista, 1853-1855", Legajos. Boletín del Archivo General de la Nación, México, Séptima Época, año 4, núm. 16, abril-junio, 2013.

BeCERril Hernández, Carlos de Jesús, "La jurisdicción contencioso administrativa fiscal en México, 1879”, en Historia y Memoria. El régimen de Porfirio Díaz, México, El Colegio de San Luis, Instituto de Investigaciones Dr. José María Luis Mora, Instituto de Investigaciones Históricas de la Universidad Michoacana de San Nicolás de Hidalgo, 2021, en prensa.

Becerril Hernández, Carlos de Jesús, "Competencia y jurisdicción de la Real Hacienda en Indias. La parte procesal de la fiscalidad: Nuevo Reino de Granada, 1793", en Ernest Sánchez Santiró (coord.), Gobierno y la administración de los erarios regios de la Monarquía Católica, México, Instituto de Investigaciones Dr. José María Luis Mora, 2021, en prensa.

CÁRDENAS SÁnchez, Enrique, El largo curso de la economía mexicana. De 1780 a nuestros días, México, El Colegio de México, Fondo de Cultura Económica, 2015.

Comín Comín, Francisco, Historia económica mundial. De los orígenes a la actualidad, España, Alianza Editorial, 2011.

Giannini, Achille Donato, Instituciones de Derecho Tributario, Madrid, Editorial de Derecho Financiero, 1957.

JÁUREGUI, Luis (coord.), De riqueza e inequidad. El problema de las contribuciones directas en América Latina, siglo XIX, México, Instituto Mora, 2006.

Jáuregui, Luis y BeCERril Hernández, Carlos de Jesús, "Diseños y transiciones fiscales en Iberoamérica, siglos XVII-XX (problemas comunes, soluciones compartidas) en Jáuregui, Luis y Becerril Hernández, Carlos de Jesús (coords.) Fiscalidad iberoamericana, siglos XVII-XX. Transiciones, diseños administrativos y jurídicos, México, Instituto Mora, Universidad Anáhuac México, 2018.

Lares, Teodosio, Lecciones de Derecho Administrativo, México, Imprenta de Ignacio Cumplido, 1852. 
Llopis, Enrique y MARICHAL, Carlos (coords.), Latinoamérica y España 18001850. Un crecimiento económico nada excepcional, México-España, Instituto Mora, Marcial Pons, 2009.

LORENTE, Marta, "Presentación", en Marta Lorente (coord.), La jurisdicción contencioso-administrativa en España. Una historia de sus orígenes, España, Consejo General del Poder Judicial, 2009.

MANNORI, Luca, "Justicia y administración entre Antiguo y Nuevo Régimen", Revista Jurídica, Madrid, Universidad Autónoma de Madrid, núm. 15, 2007. Olasagarre, Manuel, Informe que por orden de Su Alteza Serenísima presenta al supremo gobierno sobre el estado de la Hacienda pública y sus reformas, México, Imprenta de Ignacio Cumplido, 1855.

Esta obra está bajo licencia internacional Creative Commons ReconocimientoNo-Comercial-CompartirIgual 4.0.

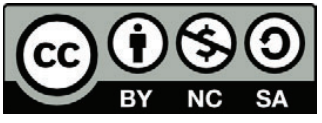

